\title{
Reflections on Evaluating in Indigenous Contexts: Looking to the Future
}

\author{
Robert P. Shepherd and Katherine A. H. Graham \\ Carleton University
}

\section{INTRODUCTION: RECALLING OUR PURPOSE}

This special edition on evaluation in Indigenous contexts had two purposes: to understand the differences between Indigenous and Western ontologies and epistemologies as these relate to research and evaluation; and to highlight the experiences and insights of researchers and evaluators who work routinely in or with Indigenous communities on research initiatives that incorporate evaluation. Creating a volume of this nature builds on the ideas of several in the field who propose that context matters where effective and relevant Indigenous research and evaluation are concerned (Cram, Chilisa, \& Mertens, 2016; Cram \& Mertens, 2015). Equally important, however, is our view that there is a dearth of research and reflection on the actual practice of evaluation in these contexts. Although there is an acknowledgment that attitudes, behaviours, and methods must be different, there is little writing on the substance and implications of these differences on evaluation practices. In this regard, explorations about how evaluators, both Indigenous and non-Indigenous, are working in and with Indigenous communities was the main insight we were looking for from the papers.

The special edition was divided into two main parts: the first part, including the introduction, contains papers that explore the legal and aspirational obligations for evaluating in Indigenous contexts; the second part relates evaluator and researcher experiences working in Indigenous contexts on actual projects. The latter set of papers provides some initial reflections on experiences with an emphasis on the challenges encountered when attempting to bridge Indigenous and Western ways of knowing. They highlight methodological challenges and the practical realities of designing and implementing projects that are meaningful to Indigenous communities. We observe three common themes emerging from the seven papers that comprise this edition.

\section{COMMON THEMES: OBSERVABLE IDEAS}

\section{Relationships are more than aspirational: There are legal obligations}

All of the papers in the volume identify the fact that the Crown's obligations to work and behave differently in relationships with Indigenous communities are

Corresponding Author: Robert Patrick Shepherd, School of Public Policy \& Administration, 1125 Colonel By Drive, Rm. 5126RB, Ottawa, ON, K1S 5B6; RobertP.Shepherd@carleton.ca 
rooted in legal as well as aspirational demands to change. The lead paper by Pam McCurry is likely unfamiliar territory for many readers of CJPE, but it is a critically important narrative that sets the tone for the papers that follow. She provides the legal context and obligations on the Crown with respect to Indigenous relations since 1982. Her paper provides a legal narrative that shows the transition from Section 91(24) under the British North America Act that exerts Crown control over Indigenous affairs to Section 35 rights that set the legal conditions for shared power and the basis for nation-to-nation relationships under self-government. Successive Supreme Court cases and challenges since 1982 have consistently attempted to define Section 35 rights, including increased local control over their affairs and all matters that affect them, which includes research and evaluation. She makes the argument that evaluation has continued to work under a Section 91(24) frame of reference that obligates Indigenous communities to participate under Crown preferences and ways of knowing. Among other things, this is contrary to the federal government's policy that builds on the United Nations Declaration on the Rights of Indigenous Peoples (UNDRIP) and the Calls to Action put forward by the Truth and Reconciliation Commission. She concludes that evaluators must understand Indigenous rights and get to know local contexts and conditions with the aim that evaluators must contribute to Indigenous sovereignty over knowledge creation.

McCurry's conclusions align well with Michelle Firestone's paper that documents the meetings of the "Three Ribbon" panel of Indigenous health and social service evaluators brought together in 2015/16 to support a partnership among four Indigenous health service organizations. The purpose of the panel was "to support the development of wise practice guidelines for high quality Indigenous health service and program evaluation through transformative, shared learning by way of discussion circles." Like McCurry, Firestone summarizes the panel's concerns with dominant (i.e., Western) evaluation systems that are externally imposed through funding agencies and agreements. She cites the various challenges to systematically gathering data that caused under-resourcing of administrative systems. She also relays that Indigenous leaders have long called on funding agencies to adopt decolonizing principles aimed at balancing control over evaluation designs and implementation (Chouinard \& Cousins, 2007) in ways that respect local governance, clarify roles and responsibilities of the evaluator and community, and ground inquiry in Indigenous knowledge systems ("Indigegogy"). As noted in other papers, she also highlights the importance of holistic concepts of good living, recognition of local community leadership, responsiveness of evaluators to local needs, and the importance of protocols in working with communities. She concludes that recognizing the granularity of local context is critical for evaluation to move forward positively and argues that evaluators would be well advised to create effective relationships prior to commencing their work.

Nicky Bowman and Larry Bremner's paper traces the roots of EvalIndigenous through the EvalPartners initiative, which begins with the premise that "all Indigenous populations have unique human rights as outlined in Article 43 
of the International Declaration on the Rights of Indigenous Peoples" and that these rights translate into obligations for "nation-to-nation" evaluations that use a co-production framework. Bowman and Bremner call for greater sovereignty over research and evaluations for Indigenous communities and organizations, which is consistent with other literature (Battiste \& Henderson, 2000; Cram \& Mertens, 2015). In addition, they make the argument that culturally appropriate approaches must become common practice in ways that are consistent with the spirit of UNDRIP. They cite the importance of approaches such as Critical Systems Theory, which maintains that activities such as evaluation are holistic efforts that incorporate power relations, governance, attitude, reciprocity, and sustainability. They argue that such theories form the basis of work with Indigenous communities and that awareness and training are needed to guide legal and aspirational imperatives into what may be called common practice.

\section{Context is critical for effective relationships: It's about building trust}

A central theme in all papers is that context is critically important when designing any research and/or evaluation effort that creates a relationship with Indigenous communities and organizations. As noted in the Introduction, acknowledging that context is critical means taking the time to understand the difference between Indigenous ontology and epistemology. Bridging these comes with several methodological challenges, as noted in the Shepherd/Graham, Delancey, McKinley, and Scott papers. However, equally important challenges emanate from Western attitudes of cultural and epistemological superiority. These attitudes assume that knowledge is understood and valued from the standpoint of individuals and that this liberal paradigm is dominant over collective notions of knowing (Bortolin, 2011). In contrast, Indigenous epistemologies assume that knowledge is relational, which means that multiple relationships to objects, people, and programs/ projects are valued from the perspective of both individuals and collectivities (Wilson, 2001, p. 176). In practice, this means that evaluation schools of thought that support more constructivist and transformative approaches are preferred. These approaches take time: getting to know communities and individuals; understanding that relationships, not power or leadership relations, are important in designing appropriate "research" efforts; and getting to know local priorities and preferences regarding research and evaluation relevance. It is equally important for the researcher/evaluator to take the time and have the local conversations that enable others to feel comfortable with her/him as an individual and have a sense of agency regarding the work ahead.

Robert Shepherd and Katherine Graham's paper situates the importance of context in terms of the Indigenous Youth Futures Partnership project that aims to understand the conditions needed to create resilient communities that support youth engagement. They emphasize the importance that pre-engagement activities played in setting up the project to establish trust with interested communities, and in creating the relationships with local leaders and youth that carry the work to desired ends. They conclude that relationships are often regarded as more 
important to nurture than Western methodological considerations for rigorous data collection.

Debbie Delancey's paper highlights the evaluation approaches used historically in the governmental context that have contributed to mistrust in the Northwest Territories. Governmental preferences have frequently taken precedence in evaluation designs, which have often been constrained by time and resources, further contributing to mistrust. She emphasizes the importance of language when communicating evaluation ideas to Indigenous communities. Given the increased participation of Indigenous governments in the delivery of programs and services, she highlights the importance of relationship building through symposia and other fora where communities have been afforded greater opportunity to steer consultation processes and lead evaluation initiatives.

Gerald McKinley's paper focuses on his experience in child and adolescent mental health programs with Anishnaabek communities. He works from an ethnographic perspective, with some training in evaluation approaches. He argues that it is important to make transparent the normative assumptions attached to concepts such as health, and that relationships to such concepts must be understood from the perspective of those living within local contexts. Through transformative approaches to evaluation, understanding programmatic conditions takes significant investments of time in order to create trust that local concerns are acknowledged in the research and evaluation endeavour.

Kimberly Scott's paper explores Indigenous inclusion in the transition to sustainable energy initiatives according to the aspirations of the Sustainable Development Goals (SDGs). Like other contributors to the volume, she maintains that understanding local priorities, needs, and approaches is essential if there is to be meaningful discussion of local energy production within an era of reconciliation. She advocates for advancing Indigenous leadership in the energy transition that is guided by some basic protocols that are jointly developed or co-produced by governments and Indigenous communities. Essential among these protocols are attention to reciprocal arrangements and measures to ensure there is fairness in both the negotiation processes and the achievement of outcomes. The contribution of evaluation to these discussions is enlightening the local context that contributes to understanding each other's needs, aspirations, and expectations.

\section{Co-production is essential: But on whose terms?}

A key theme in all papers is that affirmation of treaty rights is an obligation of settler countries such as Canada. A key part of affirming treaty rights is the development of a nation-to-nation relationship, as highlighted by McCurry, Bremner and Bowman, and Firestone. All papers, either implicitly or explicitly, identify co-production and co-creation as a necessary condition of effective relationships with Indigenous communities and organizations. Co-production is a basic characteristic of a nation-to-nation relationship.

Ideas of co-production vary from paper to paper. For example, Scott identifies co-production from a policy perspective whereby governments and communities advance energy democracy through shared ownership, meaning that 
Indigenous peoples must see themselves in local energy policy as having their own space that is under their control. Communities have the authority to decide how best to design and use that policy space to ensure that all community members have a role to play in power production with producers. McKinley highlights the importance of transformative evaluation (Cram \& Mertens, 2015), where a key feature is collaboration in the design and delivery of evaluation products. Key aspects of this collaboration are recognition of Indigenous space and the ability of the community to define the space and who can participate in it. Underlying this is the need for the researcher/evaluator to take the time to understand and recognize the local dynamics in creating the space for co-production and the conditions for working within in it. As always, co-production is dependent on respect for community preferences. In the context of health evaluation, and the identification of health outcomes in particular, co-production of both policy outcomes and evaluation approaches is central to advocacy as a fundamental pillar of transformative evaluation.

The Delancey and Shepherd/Graham papers understand co-production from a community perspective as well, but with emphasis on creating or enhancing local decision-making processes. Both papers focus on mutual respect and reciprocity as central features of co-production but recognize that culture change is needed to balance power, both in defining co-production processes and in how individuals and organizations will define what is shared and produced in the process. Although they see the need for culture change on the part of donor governments and agencies, and Indigenous communities, the need is most acute for donor governments and other non-Indigenous participants. The rebalancing of power means giving up significant control over the definition of what is shared and how to work with a more balanced co-production process that sees greater equality for Indigenous participants. Both the GNWT government, the focus of Delancey's paper, and federal donor departments in the case of the Shepherd and Graham paper are struggling to give up control over evaluation design and the manner in which evaluations are carried out. Even terms such as "leadership" or "evaluation" are being contested at the community level, as these show a predisposition for non-Indigenous priorities and preferences.

In overall terms, there are several other themes that emerge from the papers, but the three highlighted here speak to the core ideas of the special edition. The state of evaluation in Indigenous contexts is not yet at a point where basic principles such as mutual respect, reciprocity, mutual recognition, fairness, and co-production are being practised in any noticeable ways. Control over evaluation design and delivery remains firmly with donor governments and agencies. In this regard, the following are some areas where improvement is required.

\section{CHARTING A PATH FORWARD: IT'S ALWAYS ABOUT BALANCE}

We propose that several important steps can be taken that extend from the common themes gathered from the research papers. 


\section{The focus of evaluation in Indigenous contexts needs to be rethought}

As indicated in the themes section, control over the design and delivery of governmental and other donor-funded programs and services often does not reside in any substantive way with affected communities and organizations. Homogenous and pragmatic approaches to evaluation design and conduct are imposed, which serve mainly to support evaluation objectives related to expenditure management: cost efficiency. Governments in particular mainly want to know that funds are being used appropriately, rather than whether communities are benefitting from the programs and services in ways that serve or support their needs (Shepherd, 2018). Evaluations in these terms, for reasons of budget and time, do not account well for local contexts. In addition, legal relationships are often ignored in the design and conduct of evaluations that meet the tests of a nation-to-nation relationship, as described by McCurry. Equally important, the delivery of programs and services is often not well understood in communities, and when they are explored, irrelevant indicators and measures are conceived and applied in isolation from community input. In addition to federal government preferences for applying evaluation criteria of relevance and performance that are usually related to federal policy concerns, few attempts are made to apply other criteria that might be of interest to communities, such as program cohesion with other initiatives, local program capacity, or administrative effectiveness.

In addition to such design flaws, evaluators are often selected without community consultation. Such considerations almost ensure that local contexts and conditions for evaluating programs and services will be ignored, as evaluators are more than likely beholden to donor departments and agencies. Questions will be applied that matter to donors, and there may not be incentives for evaluators to seek out, let alone acknowledge, local evaluation priorities. Such factors set up evaluations to fail in Indigenous contexts. In short, if evaluation is to improve, legitimacy has to be afforded to local questions, epistemologies, and methods. Evaluation has to be decoupled in some respects from expenditure management considerations to a learning orientation that benefits communities over governments.

\section{To transform evaluation means legitimizing Indigenous ways of knowing}

As shown in all of the papers, not only does sovereignty over evaluation have to be restored to Indigenous governments and organizations (Bowman, 2017; Chilisa, 2012), but Indigenous ways of knowing also have to be acknowledged. This needs to occur in a manner that recognizes and respects the differences among Indigenous Peoples and Indigenous cultures within Canada. This is a prerequisite to adapting to the foundations and variations in circumstance among Indigenous communities and organizations. This is not easy to do from a governmental perspective, because there is a predisposition on the part of state actors to want to observe patterns and validate these so that programs and services may continue 
to be funded. Such practices open the possibility that the life or existence of the program is more important than the outcomes being felt. This is a generalization, of course, but the larger point is that governmental evaluation design tends to pay greater attention to universalistic design and conduct than to understanding Indigenous ways of knowing that focus on discrete circumstances over general observable patterns (Smith, 1999). This disjuncture means that, in effect, evaluation in Indigenous contexts is evaluation of an unknown, resulting in significantly more risk than informed practice.

In practice, governmental evaluators in particular may benefit from mapping Indigenous contexts and ways of knowing. Wilson (2001) and others acknowledge that there are likely constellations of epistemologies that could be mapped that outline cultural, political, and methodological preferences for evaluation design and conduct, but such mapping exercises will take time. Such mapping is better than current attempts at capturing the "Indigenous voice" through sampling techniques that often privilege best practices, rather than representing local needs and priorities. The challenge with current sampling strategies is that there is no way to come to reliable evaluation findings that come close to anything representative of common practice. Such mapping that includes Indigenous voice may be one tangible way to shed light on what constitutes, at the very least, appropriate evaluation practice in local contexts.

\section{There is a role for practitioner associations to enlighten understanding}

There is a role for practitioner bodies such as the Canadian Evaluation Society and other similar bodies, such as the Institute of Public Administration of Canada (IPAC), universities, think tanks, and Indigenous research centres to work together and create awareness about Indigenous contexts and epistemologies. Although some of this work is currently being done at various national and even regional conferences, perhaps greater collaboration could develop that lands on agreed messages and could work on epistemological mapping and local evaluation contexts. As scholars that work in multiple research and practice associations, we observe that there tends not to be much cross-association communication. Often there are few incentives to encourage such collaboration, despite the push to create partnerships.

We suggest that such collaborations initially emphasize a regional focus to build understanding of particular cultures and circumstances and develop appropriate relations. Delancey's paper makes the benefits of working closely with Indigenous communities apparent. The results could include greater trust and better evaluation products that take into account each other's needs. More importantly, evaluation products may improve significantly as communities work to develop greater capacity in evaluation and use the results to improve their local circumstances.

One point is clear from the papers: there is will to do better, but no roadmap on how to do that. Hopefully this special edition provides a few ways forward. 


\section{REFERENCES}

Battiste, M., \& Henderson, Y. (2000). Protecting indigenous knowledge and heritage. Saskatoon, SK: Purich Publishing.

Bortolin, K. (2011). Serving ourselves: How the discourse on community engagement privileges the university over the community. Michigan Journal of Community Service Learning, 18(1), 49-58. Retrieved from http://hdl.handle.net/2027/ spo.3239521.0018.104

Bowman, N. (2017). Asserting tribal sovereignty in evaluation and policy studies. Tribal Leader/Scholar Forum of the National Congress of American Indians-Policy Research Institute. Uncasville, CT. Retrieved from https://www.ncai.org/policy-research-center/ initiatives/tribal-leader-scholar-forum

Chilisa, B. (2012). Indigenous research methodologies. Thousand Oaks, CA: Sage.

Chouinard, J., \& Cousins, J. B. (2007). Culturally competent evaluation for Aboriginal communities: A review of the empirical research. Journal of Multi-Disciplinary Evaluation, 4(8), 40-57.

Cram, F., Chilisa, B., \& Mertens, D. M. (2016). The journey begins. In D. M. Mertens, F. Cram, \& B. Chilisa (Eds.), Indigenous pathways into social research: Voices of a new generation (pp. 11-40). New York, NY: Left Coast Press.

Cram, F., \& Mertens, D. M. (2015). Transformative and Indigenous frameworks for multimethod and mixed methods research. In S. Hesse-Biber \& B. Johnson (Eds.), The Oxford handbook of multi-methods and mixed methods research inquiry (pp. 91-110). New York, NY: Oxford University Press.

Shepherd, R. P. (2018). Indigenous peoples and the reconciliation agenda: Funding, accountability and risk. In C. Dunn (Ed.), The handbook of Canadian public administration (pp. 246-271). Don Mills, ON: Oxford.

Smith, L. T. (1999). Decolonizing methodologies: Research and Indigenous peoples. New York, NY: Palgrave.

Wilson, S. (2001). What is an Indigenous research methodology? Canadian Journal of Native Education, 25(2), 175-179.

\section{AUTHOR INFORMATION}

Robert P. Shepherd is associate professor at the School of Public Policy \& Administration at Carleton University. His research spans public management and governmental reform, Indigenous public management, ethics, and policy and program evaluation. He is interested in how public accountability and oversight systems intersect to improve overall public management and governance systems. In addition, his research extends to understanding how governmental program evaluation functions can improve public policy and decision making.

Katherine A. H. Graham is professor emerita at the School of Public Policy \& Administration at Carleton University. Her research interests concern Indigenous and northern development policy, urban and local governance, and institutional reform in government. Community-based research is an important pillar of her work. She is the founding coordinator of the Carleton University Institute on the Ethics of Research with Indigenous Peoples (CUIERIP). Katherine is currently working on youth and community capacity building in northwestern Ontario. 